\title{
Recovery of conditioned fear by a single postextinction shock: Effect of similarity of shock contexts and of time following extinction
}

\author{
WALLACE R. MCALLISTER and DOROTHY E. MCALLISTER \\ Northern Illinois University, DeKalb, Illinois
}

\begin{abstract}
Subjects in six experimental groups ( $n=16$ each) received one-trial passive avoidance (PA) training in which shock was delivered upon movement from a white wooden floor compartment to a black grid compartment. Then fear was extinguished (30 min) in the black compartment. After either 24 or $168 \mathrm{~h}$, all the groups were treated in a room distinctively different from the training room. At each interval, one group received a shock in an apparatus similar to the conditioning box, another received a shock in a dissimilar apparatus, and another was placed in a neutral box. A PA test trial in the training apparatus indicated reinstatement of extinguished fear in all the groups given a postextinction shock except the 24-h dissimilar group. Control groups revealed that the extinction treatment was effective and that spontaneous recovery was not evident. The results were explained in terms of classical conditioning, stimulus generalization, and the broadening (flattening) of stimulus generalization gradients with time.
\end{abstract}

A question of continuing interest to learning theorists is whether classically conditioned fear can ever be completely eliminated. An answer in the affirmative receives support when fear is measured by its effect on the performance of some behavior and when, following a fear extinction procedure, that behavior is no longer observed (e.g., Rescorla \& Wagner, 1972). However, it may be more in keeping with current thinking to hold that some or all of the associations formed during original fear conditioning remain following extinction (e.g., Falls, 1998; Rescorla, 2001). That is, extinction does not return the subject to its preconditioning state. Rather, from this point of view, some process occurring during the fear extinction procedure masks the expression of the associations learned during the original conditioning. The restoration of the behavior after extinction has been shown to occur when fear is increased in some manner.

Several explanations for the recovery of conditioned fear after extinction have been proposed. First, if some time elapses after a behavior has ceased, an extinguished conditioned fear response may recover spontaneously, so that the behavior is again supported (e.g., W. R. McAllister, D. E. McAllister, Scoles, \& Hampton, 1986). Second, if fear is conditioned separately to two stimuli and then fear to each stimulus is extinguished to a level that does not support a behavior, presenting the two stimuli together can lead to the restoration of that behavior (Hendry, 1982;

The authors are indebted to Edward J. Callen for helpful comments on earlier versions of the manuscript. Correspondence concerning this article should be addressed to W. R. McAllister or D. E. McAllister, Department of Psychology, Northern Illinois University, DeKalb, IL 60115 (e-mail: dmcallister@niu.edu).
Reberg, 1972). Third, reconditioning fear after extinction, in the absence of an opportunity for spontaneous recovery to occur, provides another procedure for restoring behavior. Such reconditioning has been found to proceed more rapidly than the original conditioning. This finding may be attributable to some modification's having occurred in the subject during original conditioning. Rapid reconditioning has been found not only with the fear response in rats (e.g., D. E. McAllister \& W. R. McAllister, 1994; W. R. McAllister et al., 1986), but also with the nictitating membrane response in rabbits (e.g., Macrae \& Kehoe, 1999; Napier, Macrae, \& Kehoe, 1992; Weidemann \& Kehoe, 2003), the heart rate response in rabbits (e.g., Weidemann $\&$ Kehoe, 2003), and the eyelid response in rabbits (e.g., Medina, Garcia, \& Mauk, 2001).

Two of the instances above of the recovery of behavior following the extinction of fear (the summation of two extinguished stimuli and the reconditioning of fear) are associative accounts, in that they attribute such recovery to previous conditioning or further conditioning. In contrast, a fourth account, provided by Rescorla and Heth (1975), is nonassociative. It holds that following extinction of fear to the conditioned stimulus (CS), presenting an aversive unconditioned stimulus (UCS) alone serves to inflate the value of the UCS that is degraded during extinction. Given that some associative strength between the CS and the UCS survives extinction, fear of the CS is reinstated. This account is nonassociative because the inflation is said to occur even when the UCS is presented in a situation different from the fear-conditioning situation. However, as has been pointed out by several investigators (e.g., Bouton \& Bolles, 1979; Callen, McAllister, \& McAllister, 1984; MacArdy \& Riccio, 1995), the conditioning and the reinstating situations used by Rescorla and Heth were, in actu- 
ality, highly similar, and therefore, the recovery of fear of the CS could be attributed to an associative process.

The similarity problem present in Rescorla and Heth's study (1975) was circumvented by Callen et al. (1984), who presented the postextinction shock in a highly distinctive situation. Under this condition, they found no evidence of reinstatement and, hence, no support for the nonassociative, inflation interpretation. Similarly, Bouton and Bolles (1979) reported no support for the nonassociative position when they presented the reinstating shock in a situation quite different from the original conditioning situation. Furthermore, the passive avoidance (PA) apparatus used in the study by MacArdy and Riccio (1995) for training, extinction, and testing was, except for the floors, quite dissimilar from the situation in which the postextinction shock was given. When 0 or $24 \mathrm{~h}$ intervened between extinction and the postextinction shock, they reported a failure to find a significant reinstatement of extinguished fear, a finding consistent with that of Callen et al. and Bouton and Bolles, who used a 15-min and a 24-h interval, respectively.

The experimental design employed by MacArdy and Riccio (1995) provides a fifth procedure for recovering fear following extinction. They varied the interval of time elapsing between the extinction of fear and the presentation of a postextinction shock. When the postextinction shock was given with a 1-week delay after extinction, fear was reinstated in the training situation, whereas it was not for shorter delay intervals. Because the postextinction shock was given in a situation dissimilar to the training situation, they attributed their findings to a flattening or broadening of the stimulus generalization gradient over time. Presumably, with a sufficient interval of time, the subjects were not able to discriminate between the training and the postextinction shock situations. This change in generalization gradients over time is a phenomenon that has received strong support in the literature (e.g., Desiderato, Butler, \& Meyer, 1966; W. R. McAllister \& D. E. McAllister, 1963, 1971, pp. 147-151; Perkins \& Weyant, 1958; Thomas \& Lopez, 1962). For reviews of this literature, see Riccio, Richardson, and Ebner (1984), Riccio, Ackil, and Burch-Vernon (1992), and Riccio, Rabinowitz, and Axelrod (1994).

One complicating factor in interpreting the data reported by MacArdy and Riccio (1995) is that, as they pointed out, one stimulus element, the grid floor, was identical in the PA apparatus and in the apparatus used to administer the postextinction shock. It has been demonstrated (Callen et al., 1984) that administering a postextinction shock to the tactual stimuli of a grid floor alone - that is, in darkness - is sufficient to produce reinstatement of fear that had been conditioned and then extinguished to that grid floor. As applied to MacArdy and Riccio's study, their use of identical grid floors would prevent a determination of the relative contribution to reinstatement of the reconditioning of fear to the grid floor and of the increase in the stimulus generalization of fear with time.
The review above of the previous research on the reinstatement of conditioned fear suggests that two variables have played a role in the outcomes of these studies. Specifically, they are the similarity of the apparatus used for the shock in the original training to that used for the postextinction shock and the time elapsing between extinction in the original situation and presentation of the postextinction shock. The purpose of the present study was to attempt to clarify the role of both the similarity and the temporal factors, using a PA task and procedures that were based on those employed by MacArdy and Riccio (1995).

\section{METHOD}

\section{Subjects and Design}

The subjects were 128 naive female Harlan Sprague Dawley Long Evans rats, 104-134 days of age. Nine additional subjects were discarded and replaced, 2 for exceeding a $60-\mathrm{sec}$ criterion on the PA training trial, 1 for apparatus failure, and 6 for experimenter error. The subjects were housed in pairs, and food and water were available on an ad lib basis in the home cage throughout the experiment. All the experimental treatments were administered in the light portion of a 12:12-h light:dark cycle.

The subjects were assigned in pairs, at random, to one of eight groups $(n=16$ each). The treatments administered to each of the groups on each experimental day are indicated, along with the group designations, in Table 1. For the subjects in four of the groups given PA training and extinction (E) on Day 2, a shock was administered either after $24 \mathrm{~h}$ (Day 3) or after $168 \mathrm{~h}$ (Day 9). At each temporal interval, the two groups differed with respect to the apparatus in which this postextinction shock was received. One apparatus had a floor made of grids that were identical to those used in the PA apparatus $(\mathrm{G}=$ grid floor $)$; the other had a highly dissimilar floor $(\mathrm{S}=$ solid floor). Another group at each temporal interval received PA training and extinction on Day 2 but did not receive a postextinction shock. Instead, those subjects were placed in a neutral box (NB) in order to determine whether spontaneous recovery had occurred. Two control groups (C-NE and C-E) allowed an evaluation of the adequacy of the extinction procedure.

\section{Apparatus}

The apparatus used for the PA training and the test trials consisted of a rectangular wooden box containing two separate compartments constructed of glass that was pebbled on one side and smooth on the side toward the subject. Each compartment was $248 \mathrm{~mm}$ long $\times$ $114 \mathrm{~mm}$ wide $\times 127 \mathrm{~mm}$ high. In the abutting ends of the compartments, an opening, $70 \mathrm{~mm}$ high $\times 64 \mathrm{~mm}$ wide, was centered $57 \mathrm{~mm}$ above the bottom to form a hurdle. A stainless steel assembly, fitted over the edges of the openings, contained tracks to hold a guillotine door that consisted of two pieces of glass placed in a metal frame. One compartment, used as the start box, had a glass floor. The other compartment, used for fear conditioning, had a grid floor consisting of 21 stainless steel bars, $3 \mathrm{~mm}$ in diameter, placed $11 \mathrm{~mm}$ apart (center to center). A tan paper towel was placed below the grid floor to catch any droppings. White paper was placed behind the glass walls and under the glass floor of the start box, and black paper was inserted behind the glass walls of the conditioning box. White and black papers were placed appropriately between the glass pieces of the guillotine door, so that the interior of the start box was white and that of the conditioning box, except for the floor, was black. Hinged to the top of each of the compartments was a wooden box that served as a lid. The bottom of each lid was covered with hardware cloth, $70 \mathrm{~mm}$ above which was inserted a pane of ground glass. A light bulb in the box above the start box provided constant illumination 
Table 1

Treatments for Each Group on Each Day of the Experiment

\begin{tabular}{|c|c|c|c|c|c|c|c|}
\hline Group & Day 1 & Day 2 & Day 3 & Day 4 & Days 5-8 & Day 9 & Day 10 \\
\hline $\mathrm{C}-\mathrm{NE}$ & $\mathrm{H}$ & $\mathrm{PA}+\mathrm{NE}$ & test & & & & \\
\hline C-E & $\mathrm{H}$ & $\mathrm{PA}+\mathrm{E}$ & test & & & & \\
\hline $24-G$ & $\mathrm{H}$ & $\mathrm{PA}+\mathrm{E}$ & $\begin{array}{l}\text { shock } \\
\text { grid floor }\end{array}$ & test & & & \\
\hline $24-S$ & $\mathrm{H}$ & $\mathrm{PA}+\mathrm{E}$ & $\begin{array}{l}\text { shock } \\
\text { solid floor }\end{array}$ & test & & & \\
\hline 24-NB & $\mathrm{H}$ & $\mathrm{PA}+\mathrm{E}$ & $\begin{array}{l}\text { no shock } \\
\text { neutral box }\end{array}$ & test & & & \\
\hline $168-\mathrm{G}$ & $\mathrm{H}$ & $P A+E$ & & & & $\begin{array}{l}\text { shock } \\
\text { grid floor }\end{array}$ & test \\
\hline $168-\mathrm{S}$ & $\mathrm{H}$ & $\mathrm{PA}+\mathrm{E}$ & & & & $\begin{array}{l}\text { shock } \\
\text { solid floor }\end{array}$ & test \\
\hline 168-NB & $\mathrm{H}$ & $\mathrm{PA}+\mathrm{E}$ & & & & $\begin{array}{l}\text { no shock } \\
\text { neutral box }\end{array}$ & test \\
\hline
\end{tabular}

Note - C, control; NE, no extinction; E, extinction; G, grid floor; S, solid floor; NB, neutral box; $\mathrm{H}$, handling; PA, passive avoidance training trial; test, passive avoidance test trial.

of 14.20 lx. There was no light source above the conditioning box, but dim indirect room illumination and some illumination from the start box allowed a small amount of light to be visible under the grids $(2.15 \mathrm{~lx})$.

A holding box in which each subject was placed just prior to the PA training and test trials was $200 \mathrm{~mm}$ long $\times 200 \mathrm{~mm}$ wide $\times$ $190 \mathrm{~mm}$ high. It was painted gray and had a light-colored, finegrained kitty litter on the floor and a hardware cloth lid.

The experimental room used for PA training and testing was distinctively different from the room in which the postextinction treatments were administered. The latter room was much larger and had a higher ceiling and brighter illumination. The rooms also differed with respect to the locations on the walls of the air supply and exhaust ducts, the location of the furniture in the rooms, and the location and number of bulletin boards on the walls and the materials posted on them.

For the grid floor groups, the postextinction shock was administered in a box with aluminum walls that measured $235 \mathrm{~mm}$ long $X$ $160 \mathrm{~mm}$ wide $\times 158 \mathrm{~mm}$ high. At one end, a portion of an aluminum roller hurdle (not used) projected $20 \mathrm{~mm}$ into the apparatus at grid level. The grid floor consisted of 18 stainless steel bars, $3 \mathrm{~mm}$ in diameter, placed $13 \mathrm{~mm}$ apart (center to center). The ceiling was clear Plexiglas. Overhead fluorescent lights provided illumination of 200.14 lx within the apparatus.

For the solid floor groups, the postextinction shock was given in a box constructed from two sheets of aluminum. Each sheet was bent to form one side and one half of the floor and end walls of the box. The formed sheets were attached to a wooden upright at each end of the box in such a manner that a 12-mm gap in the floor and end walls separated the two halves of the box. This construction prevented the subject from escaping shock by standing with all four feet on one side of the floor. The box measured $176 \mathrm{~mm}$ long $\times 62 \mathrm{~mm}$ wide $\times$ $100 \mathrm{~mm}$ high and had a clear Plexiglas cover. Overhead fluorescent lights provided illumination of $201.75 \mathrm{~lx}$ within the box.

The box used for the neutral box treatment was constructed of white pine and measured $250 \mathrm{~mm}$ long $\times 165 \mathrm{~mm}$ wide $\times 200 \mathrm{~mm}$ high. It had a hardware cloth top and bottom. A drop pan containing a dark-colored, coarse-grained kitty litter was placed beneath the floor of this box, as well as beneath the grid box and the solid floor box. A duplicate of this box, placed in the experimental room on a table near the PA apparatus, was used for Group $\mathrm{C}-\mathrm{NE}$.

\section{Procedure}

As is indicated in Table 1, a handling (taming) procedure was administered on Day 1. A pair of subjects were removed from their home cage in the laboratory animal room, placed in a carrying basket with wood chips on the bottom, and transported to the experimental room. Handling consisted of the subjects alternately being picked up, petted, and placed on a small table to explore. After 4 min of handling, the subjects were returned to their home cage for $15 \mathrm{~min}$ and then returned to the experimental room for an additional $4 \mathrm{~min}$ of handling. For the remainder of the experiment, the subjects were treated singly. Throughout the experiment, each time a subject was removed from or taken to its home cage, the same transportation procedure was used.

On Day 2, a PA training trial was administered to each subject. The subject was transported to the experimental room and placed, for about $1 \mathrm{~min}$, in the holding box located next to the apparatus used for the PA training. The subject was then placed in the start box of the PA apparatus facing the guillotine door. After $10 \mathrm{sec}$, the guillotine door was opened, and the subject was allowed to enter the fear-conditioning box. The door was closed immediately after all four paws were in the box, and simultaneously a 5-sec inescapable shock was administered. A stopwatch was used to measure the response latency from the opening to the closing of the door. The shock, $135 \mathrm{~V} \mathrm{AC}$, was delivered through a commutator at the rate of two pulses (approximately 13-msec duration each) per grid per second through $100-\mathrm{k} \Omega$ resistance in series with the subject. The subject was removed from the conditioning box $10 \mathrm{sec}$ after shock termination and returned to its home cage for $2 \mathrm{~min}$. Each subject, except for those in Group C-NE, was then returned to the experimental room and placed directly into the fear-conditioning box with the guillotine door closed for a 30-min fear extinction period. Each subject in Group C-NE was placed for $30 \mathrm{~min}$ in the neutral box to control for the amount of handling. After the 30-min treatment, each subject was returned to its home cage.

On Day 3, each subject in the three 24-h groups was given a postextinction treatment in the room that was distinctively different from the experimental room. Each subject was transported to this room from its home cage and was treated, depending on its group assignment, in one of the two apparatuses or in the neutral box that were located therein. Each subject in Group 24-G was placed in the grid floor apparatus, and after $10 \mathrm{sec}$, a 5 -sec shock was delivered. Each subject in Group 24-S received an analogous treatment in the solid floor apparatus. In each case, the subject was removed from the apparatus $10 \mathrm{sec}$ after shock termination. Each subject in Group 24-NB was placed in the neutral box for an equal length of time $(25 \mathrm{sec})$. Immediately following the treatment, the subject was transported to its home cage. Three other groups were counterparts of the groups described above and received identical treatments, which occurred, however, on Day 9, $168 \mathrm{~h}$, rather than $24 \mathrm{~h}$, following extinction. On Days 3-8, these subjects remained in their home cages. For each of 
the shocked groups, the shock was identical in intensity and duration and emanated from the same source as that for the shock delivered to the fear-conditioning box of the PA apparatus on Day 2.

On the following day (Day 4 for the 24-h groups and Day 10 for the 168-h groups), one PA test trial was given. This test trial was identical to the PA training trial given on Day 2, except that no shock was administered. If the subject did not enter the shock compartment within $10 \mathrm{~min}$, the trial was terminated, and a $600-\mathrm{sec}$ latency was recorded.

The PA test trial for Groups C-E and C-NE occurred on Day 3, the day following the PA training trial, and was identical to the test trial given to the other six groups.

\section{RESULTS}

To determine whether the eight groups were comparable in their tendency to make the approach response to the black box prior to the receipt of shock in that box, a Kruskal-Wallis test was carried out. It was found that the latency to enter the black box with all four paws did not differ among the groups $[H(7)=4.60, p>.71]$. The median latency of the combined groups was $10.9 \mathrm{sec}$, and the semi-interquartile range was 4.0. Inasmuch as all the subjects had been treated identically prior to this PA training trial, differences in latency among the groups following the subsequent differential treatments cannot be attributed to initial differences in their approach tendencies.

The median latency on the PA test trial is presented in Figure 1 for each of the groups. As is shown there, Group $\mathrm{C}-\mathrm{E}$, which was given the 30-min extinction treatment following the PA training trial, had a lower median latency $(22 \mathrm{sec})$ than did Group C-NE (201 sec), which did not receive the extinction treatment. A one-tailed MannWhitney test indicated, as was predicted, that the laten- cies for the C-E group were significantly lower than were those for the C-NE group $(z=1.70, p<.05)$. Therefore, it can be concluded that the extinction treatment was effective in reducing the fear that had been conditioned to the black box on the PA training trial.

As can be seen in Figure 1, for the 24-h groups, the median latency of Group 24-G on the PA test trial was longer than that of each of the other two groups. A KruskalWallis test yielded a significant difference among the three groups $[H(2)=7.97, p<.02]$. Pairwise comparisons using Mann-Whitney tests (two-tailed) revealed significantly longer latencies for Group 24-G than for Groups 24-S $(z=2.45, p<.02)$ and $24-\mathrm{NB}(z=2.34$, $p<.02)$. The latter two groups did not differ significantly $(z=0.67, p>.50)$. Thus, for the 24-h groups, the reinstatement of fear occurred only in Group 24-G.

For the 168-h groups, as is shown in Figure 1, the median latency of Group 168-G was longer on the PA test trial than that of each of the other two groups. Also, the median latency of Group 168-S was longer than that of Group 168-NB. A Kruskal-Wallis test yielded a significant difference among these three groups $[H(2)=19.78$, $p<.001]$. Pairwise comparisons using Mann-Whitney tests (two-tailed) revealed significantly longer latencies for Group 168-G than for Groups 168-S $(z=2.15, p<$ $.04)$ and $168-\mathrm{NB}(z=4.00, p<.001)$. In addition, the latencies of Group 168-S were significantly longer than those of Group 168-NB $(z=2.47, p<.02)$. Thus, in both Group 168-G and Group 168-S, fear was reinstated, but the amount was greater in the former group.

A comparison between each 24-h group and its 168-h counterpart indicated, as may be seen in Figure 1, that

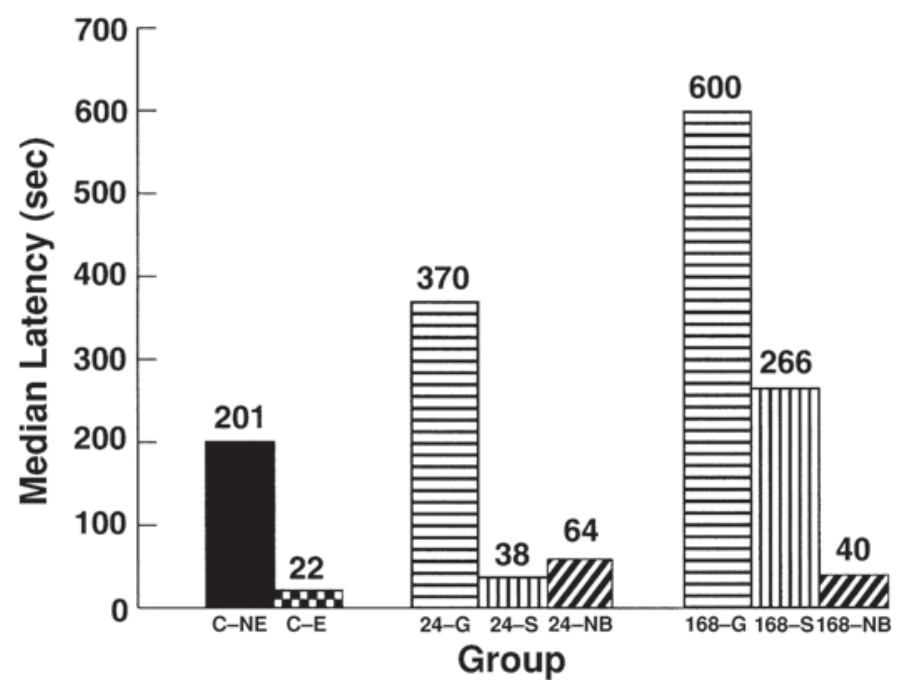

Figure 1. Median latency in seconds to enter the black conditioning compartment on the test trial for each group. Longer latencies indicate greater fear and, hence, a stronger passive avoidance response. See the text and Table 1 for details concerning the treatment of each of the groups. The semi-interquartile ranges for Groups $\mathrm{C}-\mathrm{NE}, \mathrm{C}-\mathrm{E}, \mathbf{2 4}-\mathrm{G}$, 24-S, 24-NB, 168-G, 168-S, 168-NB were 283.2, 177.0, 262.4, 61.0, 45.0, $0.30,250.7$, and 53.3, respectively. C, control; NE, no extinction; E, extinction; G, grid floor; S, solid floor; NB, neutral box. 
the 168-h groups, except under the NB condition, showed longer median latencies than did the 24-h groups. MannWhitney tests were used to evaluate these differences. For the groups receiving the postextinction shock in the grid box, the latencies of Group 168-G were significantly longer than those of Group 24-G $(z=2.56, p<.02)$, reflecting greater reinstatement of fear in the former group. Similar results were obtained for the groups given the postextinction shock in the solid floor box. Group 168-S had significantly longer latencies than did Group 24-S $(z=2.53, p<.02)$. The latencies of the two NB groups did not differ significantly $(z=0.33, p>.74)$.

The longer latencies for the 168-h groups than for their 24-h counterparts were not due simply to the effect of time itself, as was indicated by the finding that the $168-\mathrm{NB}$ and the 24-NB groups did not differ in performance. This conclusion was corroborated by a comparison among these two NB groups and Group C-E, all of which were given the extinction treatment but did not subsequently receive a postextinction shock. As may be seen in Table 1, for these groups, the PA test trial latencies were obtained on the 1st, 2nd, or 8th day following extinction. A Kruskal-Wallis test revealed that the median latencies among the three groups did not differ $[H(2)=0.19, p>.90]$. Because these latencies were not affected by the passage of time, there was no evidence for the occurrence of spontaneous recovery.

\section{DISCUSSION}

In this experiment, two variables played a role in determining the occurrence and the magnitude of the reinstatement of extinguished fear. One variable was the similarity of the shock context present during the postextinction shock treatment, relative to that present during the original conditioning and extinction of fear. The other was the time interval between the extinction-of-fear treatment and the postextinction shock treatment. The findings lend themselves to an associative explanation that relies on the application of the principles of classical conditioning. With respect to fear, when shock is presented, fear is potentially classically conditioned to all of the stimuli impinging on the subject (Hull, 1943, pp. 205-208; W. R. McAllister \& D. E. McAllister, 1965, pp. 182-186; Mowrer, 1947, p. 142). In addition, fear conditioned to a given stimulus generalizes to other, similar stimuli. Because stimulus generalization gradients of fear broaden or flatten with time, the stimuli along the dimension increase in excitatory strength (e.g., W. R. McAllister \& D. E. McAllister, 1971, p. 148). Although, in the present experiment, the gradients involved were multidimensional and not easily characterized, the same principles should be applicable.

Consider first the two groups given a postextinction shock $24 \mathrm{~h}$ following original conditioning and extinction (Groups 24-G and 24-S). It will be recalled that each subject was removed from the home cage, placed in a carrying basket, and transported to the room in which the postextinction shock was to be given. These transportation procedures were the same as those used prior to each of the various treatments administered during the original training, and hence, they would be expected to evoke a representation (memory) of the stimuli in that training situation. Because the stimuli in the postextinction shock room were quite different from those in the original training room, the subjects in the $24-\mathrm{h}$ groups presumably could discriminate easily between the two rooms.

For the postextinction shock, each subject in the 24-G group was placed in an apparatus that had a floor made of grids identical to those used for the grid floor in the PA apparatus. Presentation of the shock would condition fear to the stimuli that were impinging on the subject from the apparatus and from the room. These stimuli, except for those of the grid floor, were quite dissimilar to those in the training situation, and hence, there would be little generalization of fear of these stimuli back to the test situation. On the other hand, the fear reconditioned to the grid floor would generalize back during the test and, thus, would serve as a basis for the reinstatement that was found. Although the original fear conditioning was followed by an extinction period, it is known that a single reconditioning trial is sufficient to reestablish extinguished fear (e.g., W. R. McAllister \& D. E. McAllister, 1988; W. R. McAllister et al., 1986). As was documented in the introduction, such reconditioning has been found to occur more rapidly than original conditioning.

Each subject in the 24-S group was placed, for the postextinction shock, in a box completely different from that in which the training shock had been administered. Therefore, all of the stimuli in the apparatus and in the room to which fear would be conditioned were quite dissimilar to those present during training. Hence, generalization of fear back to the test situation would be minimal, and reinstatement would not be expected to occur. Indeed, Group 24-S did not differ from the control group (Group 24-NB) that did not receive a postextinction shock, a finding contrary to the nonassociative reinstatement position of Rescorla and Heth (1975).

Consider now the two 168-h groups. These groups were treated the same as their 24-h counterparts, except that the postextinction shock occurred 1 week, rather than 1 day, following the original conditioning and extinction. As with the 24-h groups, being transported to the room in which the postextinction shock was to be given would evoke a representation (memory) of the stimuli present in the original training situation. However, for the 168-h groups, this representation, in agreement with MacArdy and Riccio (1995), would be modified by the forgetting, over the 1-week delay, of detailed characteristics (attributes) of these stimuli. The resultant broadening of the stimulus generalization gradient would make the representation of the original conditioning situation less distinguishable from the postextinction shock situation for these groups than for the 24-h groups.

With respect to the 168-G subjects, the postextinction shock would have conditioned fear of the stimuli in the apparatus and in the room. Because these stimuli would bear some similarity to those in the original training situation, as a result of the broadening of the stimulus gen- 
eralization gradient with time, fear would be elicited by many of these stimuli, which would provide a basis for the reinstatement that occurred. The amount of reinstatement for the 168-G group would be greater than that for the 24-G group because, while fear reconditioned to the grids would generalize during the test for both groups, fear conditioned to the other stimuli would generalize importantly only for the $168-$ G group.

For the 168-S subjects, it would be expected that fear would likewise be conditioned by the postextinction shock to the stimuli in the apparatus and in the room. As with the 168-G group, fear of these stimuli, when elicited during the test, would produce reinstatement. The greater amount of reinstatement found in the 168-G group, as compared with the 168-S group, is attributable to fear being elicited also by the grid stimuli only in the former group.

This discussion has pointed up the importance of considering all of the stimuli to which fear may be conditioned when shock is presented. This is particularly important when such stimuli provide for a differential effect on a manipulated variable, such as time delay in the present study.

\section{REFERENCES}

Bouton, M. E., \& Bolles, R. C. (1979). Role of conditioned contextual stimuli in reinstatement of extinguished fear. Journal of Experimental Psychology: Animal Behavior Processes, 5, 368-378.

Callen, E. J., McAllister, W. R., \& McAllister, D. E. (1984). Investigations of the reinstatement of extinguished fear. Learning \& Motivation, 15, 302-320.

Desiderato, O., Butler, B., \& Meyer, C. (1966). Changes in fear generalization gradients as a function of delayed testing. Journal of Experimental Psychology, 72, 678-682.

FALLS, W. A. (1998). Extinction: A review of theory and the evidence suggesting that memories are not erased with nonreinforcement. In W. O'Donohue (Ed.), Learning and behavior therapy (pp. 205-229). Boston: Allyn \& Bacon.

HENDRY, J. S. (1982). Summation of undetected excitation following extinction of the CER. Animal Learning \& Behavior, 10, 476-482.

Hull, C. L. (1943). Principles of behavior: An introduction to behavior theory. New York: Appleton-Century.

MacArdy, E. A., \& Riccio, D. C. (1995). Time-dependent changes in the effectiveness of a noncontingent footshock reminder. Learning \& Motivation, 26, 29-42.

Macrae, M., \& Kehoe, E. J. (1999). Savings after extinction in conditioning of the rabbit's nictitating membrane response. Psychobiology, 27, 85-94.

McAllister, D. E., \& McAllister, W. R. (1994). Extinction and reconditioning of classically conditioned fear before and after instrumental learning: Effects of depth of fear extinction. Learning \& Motivation, 25, 339-367.

McAllister, W. R., \& McAllister, D. E. (1963). Increase over time in the stimulus generalization of acquired fear. Journal of Experimental Psychology, 65, 576-582.
McAllister, W. R., \& McAllister, D. E. (1965). Variables influencing the conditioning and the measurement of acquired fear. In W. F. Prokasy (Ed.), Classical conditioning: A symposium (pp. 172-191). New York: Appleton-Century-Crofts.

McAllister, W. R., \& McAllister, D. E. (1971). Behavioral measurement of conditioned fear. In F. R. Brush (Ed.), Aversive conditioning and learning (pp. 105-179). New York: Academic Press.

McAllister, W. R., \& McAllister, D. E. (1988). Reconditioning of extinguished fear after a one-year delay. Bulletin of the Psychonomic Society, 26, 463-466.

McAllister, W. R., McAllister, D. E., Scoles, M. T., \& Hampton, S. R. (1986). Persistence of fear-reducing behavior: Relevance for the conditioning theory of neurosis. Journal of Abnormal Psychology, 95, 365-372.

Medina, J. F., Garcia, K. S., \& Mauk, M. D. (2001). A mechanism for savings in the cerebellum. Journal of Neuroscience, 21, 4081-4089.

Mowrer, O. H. (1947). On the dual nature of learning: A re-interpretation of "conditioning" and "problem-solving." Harvard Educational Review, $17,102-148$.

Napier, R. M., Macrae, M., \& Kehoe, E. J. (1992). Rapid reacquisition in conditioning of the rabbit's nictitating membrane response. Journal of Experimental Psychology: Animal Behavior Processes, 18, 182-192.

Perkins, C. C., JR., \& Weyant, R. G. (1958). The interval between training and test trials as a determiner of the slope of generalization gradients. Journal of Comparative \& Physiological Psychology, 51, 596-600.

ReberG, D. (1972). Compound tests for excitation in early acquisition and after prolonged extinction of conditioned suppression. Learning \& Motivation, 3, 246-258.

Rescorla, R. A. (2001). Experimental extinction. In R. R. Mowrer \& S. B. Klein (Eds.), Handbook of contemporary learning theories (pp. 119-154). Mahwah, NJ: Erlbaum.

Rescorla, R. A., \& Heth, C. D. (1975). Reinstatement of fear to an extinguished conditioned stimulus. Journal of Experimental Psychology: Animal Behavior Processes, 1, 88-96.

Rescorla, R. A., \& Wagner, A. R. (1972). A theory of Pavlovian conditioning: Variations in the effectiveness of reinforcement and nonreinforcement. In A. H. Black \& W. F. Prokasy (Eds.), Classical conditioning II: Current research and theory (pp. 64-99). New York: Appleton-Century-Crofts.

Riccio, D. C., ACKIL, J., \& Burch-Vernon, A. (1992). Forgetting of stimulus attributes: Methodological implications for assessing associative phenomena. Psychological Bulletin, 112, 433-445.

Riccio, D. C., Rabinowitz, V. C., \& Axelrod, S. (1994). Memory: When less is more. American Psychologist, 49, 917-926.

Riccio, D. C., Richardson, R., \& Ebner, D. L. (1984). Memory retrieval deficits based upon altered contextual cues: A paradox. Psychological Bulletin, 96, 152-165.

Thomas, D. R., \& Lopez, L. J. (1962). The effects of delayed testing on generalization slope. Journal of Comparative \& Physiological Psychology, 55, 541-544.

Weidemann, G., \& Kehoe, E. J. (2003). Savings in classical conditioning in the rabbit as a function of extended extinction. Learning \& Behavior, 31, 49-68.

(Manuscript received March 18, 2003; revision accepted for publication April 13, 2005.) 